\title{
Unidad de la ciencia en el pensamiento de Humbolt
}

\author{
Oswaldo Báez Tobar
}

Universidad Central del Ecuador

oswaldobaez@hotmail.com

Para entender la amplitud del pensamiento científico de Alexander von Humboldt y su proyecto científico es preciso mencionar la preparación académica que recibió en la Universidad de Berlín, Gotinga, Hamburgo y en la Escuela de Minas de Freiberg. Estudió matemática, botánica, zoología, anatomía comparada, geografía, geología, vulcanología; minería, lenguas, historia de la cultura, economía política nacional e internacional, además dibujo y grabado. Se relacionó con las más distinguidas personalidades de la cultura y ciencia europea: Johann Goethe, Johann Blumenback (zoólogo), Karl Ludwig Willenou (botánico), Georg Forster (geólogo), Cuvier (zoólogo), Gay-Lussac y Bethelot (químicos), Laplace (astrónomo).

Humbldt se preparó para su proyecto científico. Sus primeros 30 años los dedicó a su preparación para el viaje de estudio en tierras equinocciales de América que le tomaría cinco años; trabajó 50 años en el análisis e interpretación de datos, la preparación y publicación de los libros que contienen su gran obra científica. "Mi verdadera y única finalidad es investigar cómo se entretejen todas las fuerzas naturales, la influencia de la naturaleza muerta sobre el mundo vivo animal y vegetal". El viaje a América tuvo lugar entre 1799 y 1804, visitó Venezuela, Cuba, Colombia, Ecuador, Perú, México y Estados Unidos. (Mayer-Abich, 1985).

Los conocimientos científicos de Humboldt fueron los más avanzados de su época; a eso se sumó el dominio del método y técnicas de investigación científica. Sostuvo que no puede haber conocimiento científico sin demostración verificable. Empleó numerosos instrumentos de observación y medición geofísica: sextante, cronómetro, hipsómetro, barómetro, telescopio; inclinómetro y declinómetro; termómetro y aerómetro; eudiómetro, electrómetro y el higrómetro, cianómetro... Y estudió las plantas y los animales en relación con las condiciones ambientales. Además observó y describió a las personas que vivían en cada paisaje, en sus contextos sociales, económicos, políticos e históricos, con lo cual logró la aprehensión de la realidad total. 


\section{Contribución científica}

La principal contribución a la ciencia consta en los textos sudamericanos y otras publicaciones:

- Viaje a las regiones equinocciales del Nuevo Continente. Obra en 35 volúmenes, publicados en París entre 1805-1834. Incluye varias obras subordinadas, entre ellas: Ensayo sobre la geografía de las plantas, acompañado de una tabla fisica de las regiones equinocciales (1807), y Nova génera de especies de plantas, que contiene la descripción de más de 4000 especies de plantas, Humboldt, Bonpland $\mathrm{y}$ Kunth.

- Observaciones Zoológicas y Anatomía Comparada, París, 1799-1803.

- Cuadros de la Naturaleza.

Cosmos. Contiene una descripción del mundo físico que había observado y estudiado durante 50 años; representa la síntesis filosófica de todos los conocimientos de su tiempo.

- Contribuciones a la cartografía mediante el levantamiento de mapas físicos de algunas regiones visitadas y perfiles de mapas de asociaciones vegetales.

- Concepción de varios principios científicos: de la relación entre la latitud y la altitud, unidad dinámica de la naturaleza y del principio de la continentalidad, este último luego de viajar a Rusia y comparar las observaciones de América y Asia.

\section{Contribución a la Botánica y la Fitogeografía}

Los aportes a la botánica morfológica y botánica sistemática fueron importantes; pero la contribución científica mayor está en la geografía de las plantas o fitogeografía. En el Ensayo sobre la geografía de la plantas (terminado en Guayaquil en 1803) Humboldt resume las más innovadoras concepciones de la geología, historia de las plantas, taxonomía, ecología, distribución de las plantas y el transformismo. (Zúñiga, 1964). Es, por lo mismo, una síntesis de conceptos y principios de varias ciencias naturales para explicar la regularidad en la distribución de las plantas y las formaciones vegetales. "La geografía de las plantas hizo visibles los variados mosaicos paisajísticos y su interrelación funcional y propuso la idea de la unidad dinámica y variada de la naturaleza" (Castrillón, 2001).

\section{Contribución a la Ecología}

La base conceptual inicial de la ecología es otra de las contribuciones de Humboldt; está contenida en el entendimiento humboldtiano de "las interrelaciones entre los organismos entre sí y con su entorno animado e inanimado". En esta concepción se halla el núcleo de la ecología. Humboldt se propuso "reunir datos para ampliar una ciencia que apenas está en esbozo y falta definición, que en ocasiones es llamada Física del mundo, Teoría de la Tierra, Geo- 
grafía física". (Holl, 2001). Esta concepción sustenta a la ecología, aunque la denominación de ecología se debió a Ernest Haeckel en 1866.

El paisaje como término científicogeográfico fue también introducido a principios del siglo XIX por Humboldt al definir al paisaje como la totalidad de características de una región de la Tierra, que abarca la fisiografía, geología y geomorfología regional. (Naveh \& Lieberman, 1990). De la conjunción de la ecología y el paisaje surgió la Ecología del Paisaje, que es la descripción de un área geográfica a base de los factores que lo generan: suelo, latitud y altitud, el clima y sus elementos: temperatura, pluviosidad, heliofanía, vientos, humedad ambiental, y la descripción de la cubierta vegetal como el reflejo de su ecología. Bajo el concepto de paisaje, la naturaleza es concebida como un mosaico de unidades definibles: el paisaje ecológico (cuya definición global fue desarrollada en por el geógrafo y botánico alemán Carl Troll en 1938).

Humboldt consideró al paisaje como un espacio de interrelación dentro de la naturaleza y también entre el ser humano y la naturaleza. Así prefiguró una visión integradora y globalizante, que casi dos siglos después se concretó en la macroecología, disciplina que surgió de la necesidad de aprehender la realidad regional y global del mundo viviente. La macroecología tiene la virtud de ampliar la visión más allá del ecosistema, del paisaje, de la ecorregión... para abarcar escalas superiores. La macroecología es una nueva manera de estudiar las relaciones entre los organismos y su ambiente; esto implica caracterizar y explicar los patrones estadísticos de abundancia, distribución y diversidad, para lo cual trabaja a escalas espaciales y temporales grandes, según James Brown (2003). En los trabajos de Humblodt se encuentra el germen del enfoque macroecológico para el estudio de la naturaleza viviente.

\section{La unidad de la Ciencia en el pensamiento de Humboldt}

Humboldt fue formado en la observación y experimentación científica de exigencia y reflexión newtonianas, de hondura y rigor kantianos, y amplitud enciclopedista. Hombre sabio con sensibilidad para lo natural y lo humano. Tuvo una capacidad intelectual extraordinaria para relacionar el mundo natural y humano. Humboldt logró conocer distintas ramas de la ciencia; su deseo fue discernir los fenómenos físicos en su interconexión para comprender a la naturaleza como un todo... (Meyer-Alich, 1985). La naturaleza aprehendida por la ciencia cultivada por Humboldt aflora como una unidad en la diversidad de los seres y fenómenos que lo constituyen, entre los cuales existe armonía. 
He aquí la clave para entender el pensamiento humboldtiano: la unidad de la naturaleza expresada en la unidad y totalidad de la ciencia. Humboldt buscó la comprensión integral de la Tierra como un todo orgánico, como un cosmos. Así la visión y comprensión integral de la ciencia alcanzó con Humboldt su apogeo y su culminación histórica.

"Sé muy bien que no estoy a la altura de mi gran obra sobre la naturaleza. Esta empresa es un poco grande para un particular, pero no es deshonra sucumbir ante un gran proyecto. El ser humano debe querer lo grande y bueno" afirmó Humboldt en el ocaso de su vida. Este es el mensaje del gran científico y humanista. En esta frase expresa la relación necesaria entre las ciencias naturales y las humanidades.

\section{BIBLIOGRAFÍA}

Brown, J. 2003. Macroecología. Fondo de Cultura Económica. México.

Castrillón, A. 2001. Humboldt: los viajes, las naturalezas y las ciencias. En: El regreso de Humboldt. Exposición en el Museo de la Ciudad de Quito, junio-agosto 2001.

Holl, F. 2001. El regreso de de Humboldt: Alexander von Humboldt en Colombia y Ecuador. En: El regreso de Humboldt. Exposición en el Museo de la Ciudad de Quito, junio-agosto 2001.

Meyer-Abich, A. 1985. Humboldt. Salvat Editores, S. A., Barcelona.

Naveh, Z., Lieberman, A. 1990. Landscape Ecology: Teoría y Aplicación. Spriger-Verlag, New York.

Zúñiga, N. 1964. Humboldt y la Geografía de las Plantas. Talleres Gráficos Nacionales, Quito. 